\title{
European survey on laboratory preparedness, response and diagnostic capacity for Crimean-Congo haemorrhagic fever, 2012
}

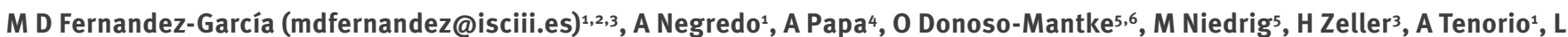
Franco $^{1}$, the ENIVD members ${ }^{7}$

1. National Microbiology Centre, Instituto de Salud Carlos III, Madrid, Spain

2. European Public Health Microbiology Training Programme (EUPHEM)

3. European Centre for Disease Prevention and Control (ECDC), Stockholm, Sweden

4. Department of Microbiology, National Reference Centre for Arboviruses, Medical School, Aristotle University of Thessaloniki, Thessaloniki, Greece

5. Zentrum für Biologische Gefahren und Spezielle Pathogene (ZBS-1), Robert Koch Institute, Berlin, Germany

6. Present address: Gesellschaft fuer Biotechnologische Diagnostik mbH, Berlin, Germany

7. The ENIVD members are listed at the end of the article

Citation style for this article:

Fernandez-García MD, Negredo A, Papa A, Donoso-Mantke O, Niedrig M, Zeller H, Tenorio A, Franco L, the ENIVD members. European survey on laboratory

preparedness, response and diagnostic capacity for Crimean-Congo haemorrhagic fever, 2012. Euro Surveill. 2014;19(26):pii=20844. Available online: http://www. eurosurveillance.org/ViewArticle.aspx?Articleld=20844

Article submitted on 23 August 2013 / published on 03 July 2014

Crimean-Congo haemorrhagic fever (CCHF) is an infectious viral disease that has (re-)emerged in the last decade in south-eastern Europe, and there is a risk for further geographical expansion to western Europe. Here we report the results of a survey covering 28 countries, conducted in 2012 among the member laboratories of the European Network for Diagnostics of 'Imported' Viral Diseases (ENIVD) to assess laboratory preparedness and response capacities for CCHF. The answers of 31 laboratories of the European region regarding CCHF case definition, training necessity, biosafety, quality assurance and diagnostic tests are presented. In addition, we identified the lack of a Regional Reference Expert Laboratory in or near endemic areas. Moreover, a comprehensive review of the biosafety level suitable to the reality of endemic areas is needed. These issues are challenges that should be addressed by European public health authorities. However, all respondent laboratories have suitable diagnostic capacities for the current situation.

\section{Introduction}

Crimean-Congo haemorrhagic fever (CCHF) is a zoonotic viral disease caused by the tick-borne CCHF virus (CCHFV), which is classified into the genus Nairovirus within the Bunyaviridae family. In humans, the disease is highly pathogenic and life-threatening as it can cause severe illness with prominent haemorrhages reaching case fatality rates of up to $50 \%$. In nature, CCHFV usually circulates between asymptomatic animals and ticks in an enzootic cycle. Humans may become infected through the bite of a tick, mainly of the Hyalomma genus, through direct contact with blood or tissues from viraemic livestock or through direct contact with the blood or secretions of a viraemic patient
[1]. Thus, risk groups include individuals with outdoor activities, mainly those who have occupational contact with animals, as well as healthcare workers in hospital settings (nosocomial hazard). Because of the potential for epidemics and nosocomial outbreaks, high fatality ratio, limitations for treatment and the lack of safe vaccine, CCHF is a disease listed for immediate notification to public health authorities as it constitutes a major threat to public health. Therefore, CCHFV is considered a high-risk pathogenic organism and classified as a biosafety level (BSL) 4 containment agent.

The disease is endemic in wide areas of Africa, the Middle East, central and south-western Asia and the south-eastern European region. More particularly, some Balkan countries (e.g. Albania, Bulgaria, Greece and Kosovo under UN Security Council Resolution 1244) are endemic zones for CCHF [2]. During the last decade, CCHF re-emerged in Albania, Greece, Kosovo under UN Security Council Resolution 1244 and countries bordering the Black sea: Georgia, south-western Russia Turkey, and Ukraine. In Greece, the detection of the non-pathogenic strain AP92 in ticks in 1975 was followed by the notification of the first human CCHF case in June 2008 [3]. However, the vast majority of CCHF cases have been recorded in Turkey (since 2002) and the south-western regions of Russia (since 1999), with expanding outbreaks and increasing numbers of associated fatalities [2]. In northern and south-western Europe, no human cases have been reported except for imported ones in France [4], Germany [5] and the United Kingdom [6]. Limited serological evidence in humans has been reported in parts of Hungary and Portugal $[7,8]$. 
In Europe, the tick vector most commonly associated with CCHFV is Hyalomma marginatum, which is present in southern Europe and has sporadically been detected in southern Germany, the Netherlands and the United Kingdom following expansion of its geographical range associated with movement of migrant breeding birds [9-12]. The spreading of the vector represents a risk factor for introduction of the virus from endemic to unaffected areas of Europe, increasing the occurrence of CCHF [13]. However, virological evidence has never been addressed in western Europe until 2010, when a study conducted in Spain detected for the first time CCHFV in populations of $H$. lusitanicum collected from indigenous deer [14]. Moreover, the recent discovery of antibodies against CCHFV in livestock in Romania, with prevalence values similar to those observed in other regions where the disease is endemic, suggests an extension of the circulation zone of CCHFV in Europe [15].

In 2008, after the first case in Greece was detected, the European Centre for Disease Prevention and Control (ECDC) organised an expert consultation on CCHF to identify preparedness interventions in Europe [13]. In 2011, under the initiative of the European Network for Diagnostics of 'Imported' Viral Diseases (ENIVD; www.enivd.org), a multicenter study of CCHF diagnostic tests and an external quality assessment

TABLE 1

ENIVD survey on Crimean-Congo haemorrhagic fever, responding laboratories, by country, $2012(\mathrm{n}=31)$

\begin{tabular}{|c|c|c|c|}
\hline Participating countries & Participating laboratories & $\begin{array}{l}\text { Acts as } \\
\text { NRL }\end{array}$ & WHOCC \\
\hline Austria & Medical University of Vienna, Vienna & No & No \\
\hline Belgium & Institute of Tropical Medicine, Antwerpen & Yes & No \\
\hline Bulgaria & National Centre for Infectious and Parasitic Diseases, Sofia & Yes & No \\
\hline Croatia & University Hospital for Infectious Diseases, Zagreb & No & No \\
\hline Czech Republic & Institute of Public Health, Ostrava & No & No \\
\hline Estonia & National Institute for Health Development/Health Board, Tallinn & No & No \\
\hline $\begin{array}{l}\text { Former Yugoslav Republic } \\
\text { of Macedonia }\end{array}$ & Institute of Health Protection of the FYROM & No & No \\
\hline \multirow{2}{*}{ France } & 1. Institut Pasteur, Lyon & Yes & Yes \\
\hline & 2. Aix-Marseille University and AP-HM Public Hospitals, Marseille & No & No \\
\hline \multirow{2}{*}{ Germany } & 1. Bernhard-Nocht Institut, Hamburg & Yes & Yes \\
\hline & 2. Institut für Mikrobiologie der Bundeswehr, Munich & No & No \\
\hline Greece & Aristotle University, Thessaloniki & Yes & $\begin{array}{c}\text { No } \\
\text { (discontinued } \\
\text { since } 20 / \\
\text { Oct/2008) }\end{array}$ \\
\hline Italy & National Institute for Infectious Diseases “L.Spallanzani”, Rome & Yes & Yes \\
\hline $\begin{array}{l}\text { Kosovo under UN Security } \\
\text { Council Resolution } 1244\end{array}$ & National Institute of Public Health of Kosovo, Pristina & Yes & No \\
\hline Latvia & Infectology Center of Latvia, Riga & Yes & No \\
\hline Lithuania & National Public Health Surveillance Laboratory, Vilnius & Yes & No \\
\hline Malta & Mater Dei Hospital, Valletta & No & No \\
\hline The Netherlands & Erasmus University Hospital, Rotterdam & Yes & Yes \\
\hline Norway & Norwegian Institute of Public Health, Oslo & Yes & No \\
\hline Portugal & National Institute of Health, Águas de Moura & Yes & No \\
\hline Romania & National Institute of Public Health, Bucharest & Yes & No \\
\hline Russia & Central Research Institute of Epidemiology, Moscow & Yes & No \\
\hline Serbia & Torlak Institute of Virology, Belgrade & Yes & No \\
\hline Slovakia & Institute of Virology, Slovak Academy of Sciences, Bratislava & No & No \\
\hline Slovenia & University of Ljubljana, Ljubljana & Yes & $\begin{array}{c}\text { No } \\
\text { (discontinued } \\
\text { since } 1 / \\
\text { Sep/2008) }\end{array}$ \\
\hline Spain & Instituto de Salud Carlos III, Madrid & Yes & No \\
\hline Sweden & $\begin{array}{l}\text { Swedish Institute for Infectious Disease Control, Karolinska Institute Stockholm, } \\
\text { Solna }\end{array}$ & Yes & No \\
\hline Switzerland & University Hospitals of Geneva, Geneva & Yes & No \\
\hline Turkey & Refik Saydam Hygiene Institute, Ankara & Yes & No \\
\hline \multirow{2}{*}{ United Kingdom } & 1. Public Health England, Colindale & No & No \\
\hline & 2. Public Health England, Porton Down & Yes & Yes \\
\hline
\end{tabular}

ENIVD: European Network for Diagnostics of 'Imported' Viral Diseases; NRL: National Reference Laboratory; WHOCC: World Health Organization Collaborating Center (http://apps.who.int/whocc/) for Viral Haemorrhagic Fevers from the EURO region.

${ }^{a}$ Discontinued means that the institution is no longer a WHOCC. 
(EQA) for CCHF molecular diagnosis were carried out to monitor and compare the performance of the different techniques applied for diagnosis of CCHF $[16,17]$. The current situation with continous high transmission in Turkey and south-western Russia, new imported cases in the European Union (EU), detection of the virus for the first time in the western Mediterranean region, and new evidence of seroprevalence in animals, make necessary a new assessment on preparedness and laboratory capacities for CCHF in the European region. Here, we describe the results of a questionnaire survey conducted in 2012 to assess the laboratory preparedness and response capacities for CCHF diagnosis in the European region.

\section{Methods}

To gather information on CCHF diagnostics, preparedness and response capacities in Europe, a questionnaire was developed and sent electronically in January 2012 to laboratory contact points in the ENIVD database, covering 28 Member States of the EU as well as nine non-EU countries, Russia, Norway, Switzerland, Bosnia and Herzegovina, Serbia, Kosovo under UN Security Council Resolution 1244, Albania, the Former Yugoslavia Republic of Macedonia and Turkey. All completed questionnaires were received by April 2012. The first part of the questionnaire assessed preparedness and response capacities, while the second part was designed to collect information on diagnostic capacities and quality assurance. Questions on the following topics were included in the questionnaire: $\mathrm{CCHF}$ case definition, training necessity, biosafety assurance, diagnostic tests and quality assurance. The list of respondents is shown in Table 1 . Respondents were National Reference Laboratories (NRL) for Arbovirus and Viral Haemorrhagic Fever (VHF) and/or World Health Organization Collaborating Centers (WHOCC). An NRL was defined as a laboratory involved in reception/management of suspected samples of CCHF, either for diagnostic and reference activities or for shipment abroad in case of lack diagnostic capacity

\section{Results}

\section{Participation}

Sixty-eight laboratories from 37 countries (28 EU Members States and nine countries outside the EU), were contacted for this survey. Thirty-one laboratories from 28 countries returned their answer, except Albania, Bosnia and Herzegovina, Cyprus, Denmark,

\section{FIGURE 1}

Diagnostic capacities and occurrence of Crimean-Congo haemorrhagic fever in Europe since 2000

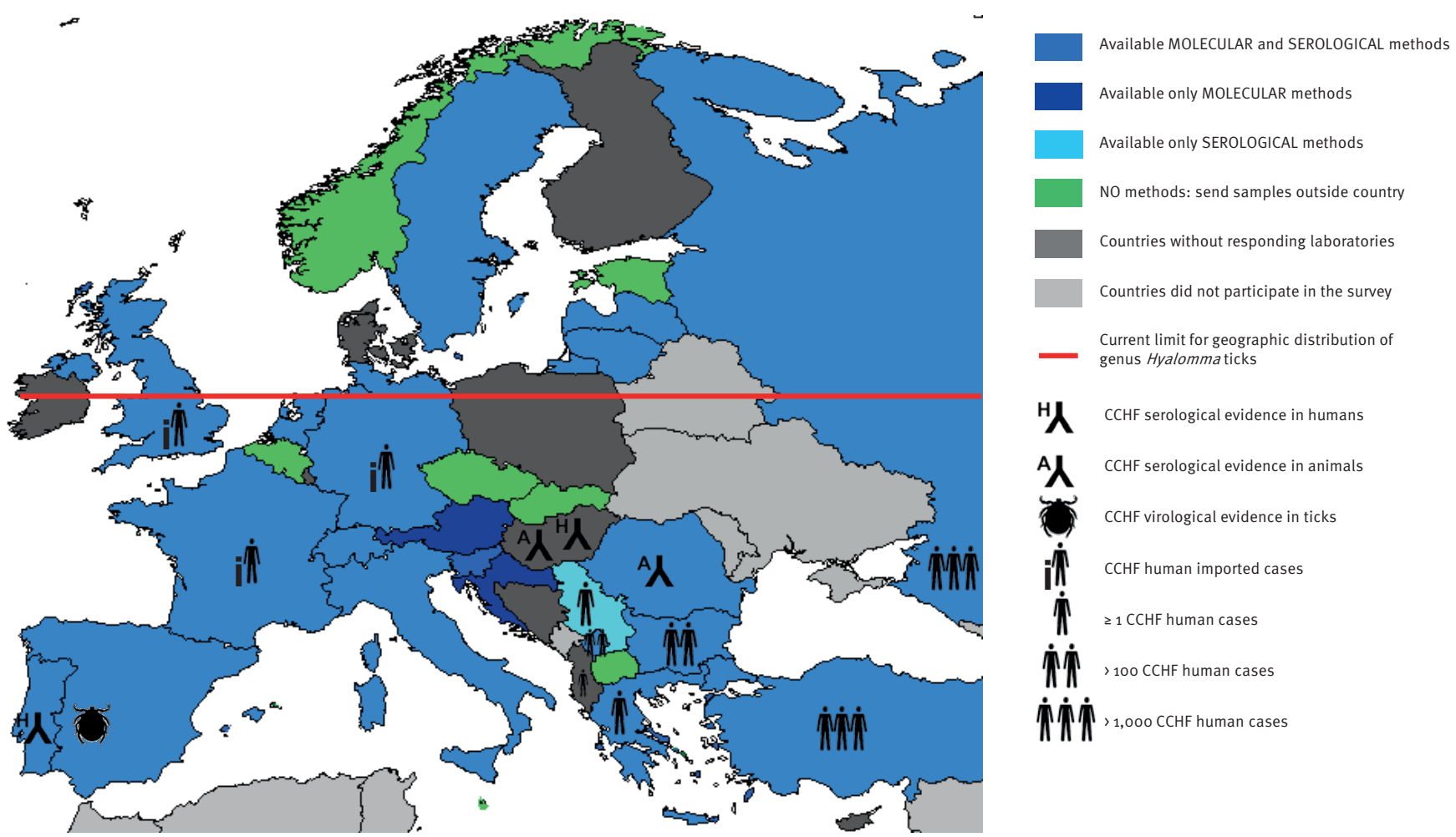

CCHF: Crimean-Congo haemorrhagic fever; ECDC: European Centre for Disease Prevention and Control; WHO: World Health Organization.

Colour code indicates diagnostic capacities as assessed in the present survey. Human silhouettes indicate occurrence of $\mathrm{CCHF}$ in humans according to the WHO database (http://data.euro.who.int/cisid), the ECDC consultation [13] and the Public Health England database (http:// www.hpa.org.uk/Topics/InfectiousDiseases/InfectionsAZ/CCHF/EpidemiologicalData/cchfoutbreaks/). Tick silhouettes indicate virological evidence of CCHF in ticks in those countries where no human cases have been reported. Antibody silhouettes indicate serological evidence of CCHF in humans or animals in countries where no human cases have been reported. 


\section{FIGURE 2}

Application of Crimean-Congo haemorrhagic fever molecular diagnostic methods, ENIVD survey, 2012 ( $\mathrm{n}=23$ laboratories)

A. Percentage of countries using commercial molecular tests

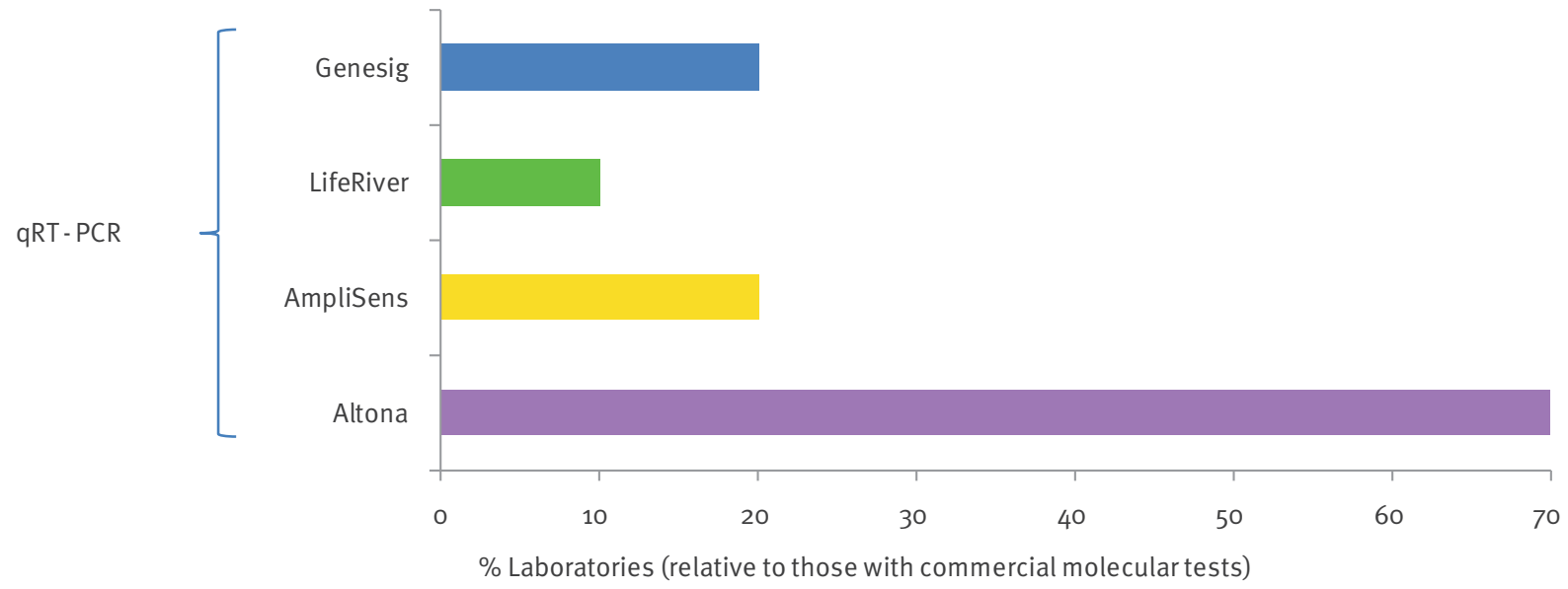

B. Percentage of countries using in-house molecular tests

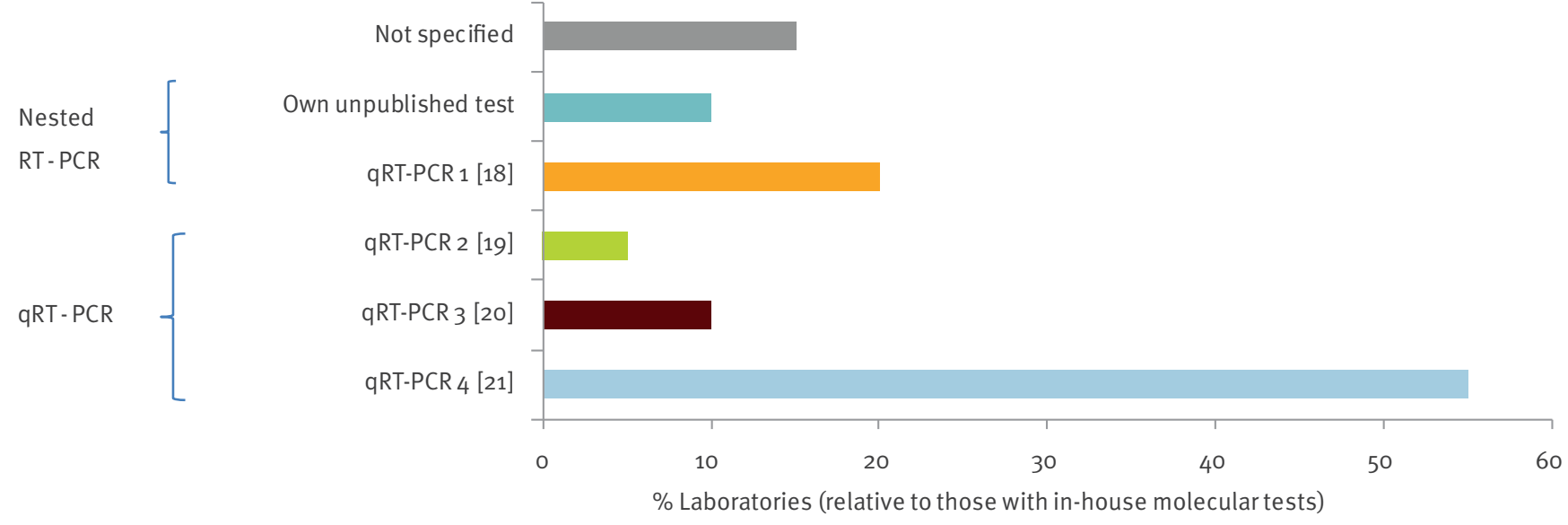

Kosovo under UN Security Council Resolution 1244, Romania

Latvia

Lithuania, Russia

Germany (Hamburg, Munich), Greece, Kosovo under UN Security Council Resolution 1244, Portugal, Slovenia, Turkey

France Lyon, Germany Munich, Romania

The Netherlands, Russia, Spain

Bulgaria, Croatia, Greece, Slovenia

Slovenia

- Greece, Italy

- Austria, France Marseille, Germany Hamburg, Greece, Kosovo under UN Security Council Resolution 1244Sweden, United Kingdom Colindale, United Kingdom Porton Down

ENIVD: European Network for Diagnostics of 'Imported' Viral Diseases; qRT-PCR: quantitative real-time reverse transcription polymerase chain reaction; RT-PCR: reverse transcription polymerase chain reaction. 
Finland, Hungary, Ireland, Luxembourg and Poland, corresponding to a participation of $76 \%$ of the countries and $45 \%$ of the laboratories. Of all laboratories that participated in the survey, 21 acted as a NRL for VHF and five act as a WHOCC.

\section{Preparedness and response}

All respondent laboratories declared that CCHF was a notifiable disease in their countries and that they followed the generic case definition for VHFs, while six countries (Bulgaria, Greece, Germany, Turkey, Russia and Spain) had their own case definition for CCHF (Table 2).

Most laboratories (25/31) stated that they had trained staff authorised to handle CCHF samples and that there was trained staff in their countries skilled in assessing VHF cases/outbreaks; 19 laboratories emphasised a need for further training, not only for laboratory workers, but also for medical and nursing staff. Half of the 24 laboratories with CCHF diagnostic capacity stated their availability to offer training services for CCHF diagnosis to other laboratories in and outside their countries.

Of all responding laboratories, 20 had standardised procedures for specimen collection and storage of CCHF infected material, and 25 for processing and shipping suspected CCHF specimens for confirmation diagnosis in other laboratories.

\section{Diagnostic capacities}

Of the 31 laboratories that participated in the survey, 24 declared to have set up diagnostic capacities to detect CCHF infection. The remaining seven laboratories in countries where CCHF diagnostic capacities has not yet been established, declared that they were sending samples to reference laboratories or WHOCCS outside their countries (Figure 1).

Among the 24 laboratories with diagnostic capacities, all except the laboratory in Serbia had CCHF molecular tests based on either quantitative real-time reverse transcription polymerase chain reaction ( $q R T-P C R)$ or nested RT-PCR. Information on the type of commercial or in-house protocol used was requested from the participants. Among the 23 laboratories which performed CCHF molecular diagnosis, 20 used an inhouse method, 11 used commercial assays and eight combined both in-house and commercial approaches (Figure 2).

The serological diagnosis of CCHFV infection is based on the detection of specific IgM and IgG antibodies against recombinant nucleoprotein as the predominant available antigen, either in an enzyme-linked immunosorbent assay (ELISA) or in an indirect immunofluorescence assay (IFA). Most laboratories (22/24) with diagnostic capacities had available at least one serological technique, ELISA or IFA. Respondents were also asked about the availability of specific in-house or commercial (Vector-Best, Novosibirsk, Russia) ELISA tests for CCHF as well as in-house or commercial (Eurolmmun, Luebeck, Germany) IFA (Table 2).

Eleven of 21 countries declared doing research to improve in-house molecular methods, and six of the 21 declared investigating also new serological in-house methods.

Regarding quality assurance, this survey revealed that 19 of the 23 laboratories with molecular diagnostic methods participated in the EQA on CCHF molecular diagnosis organised by ENIVD in 2011 [16], while only four participated in the exercise organised by the Quality Assurance exercise and Networking on the Detection of Highly Infectious Pathogens (QUANDHIP) project (www.quandhip.info) (Table 3).

\section{Biosafety}

The 24 laboratories with diagnostic capacities informed about the inactivation process before handling specimens for diagnostic purpose. Among them, six laboratories inactivated specimens under BSL4, 12 in $B S L 3$ and five in BSL2 conditions (Figure 3). Of 11 laboratories performing viral isolation and propagation, six did so in BSL4 facilities and five in lower-grade BSL facilities.

\section{Discussion}

This survey has been carried out in 28 countries of the European region, including 10 countries where human cases are frequently or sporadically reported, or where there has been evidence of CCHFV circulation in animals or ticks. The presence of potential CCHFV vectors in other European countries may extend the current geographical distribution of the disease. In addition, imported cases in travellers have been reported in the EU. Hence, early recognition of the suspected CCHF cases is critical, in order to initiate the proper treatment of the patient and to apply control measures for containment of the disease. Some authors argue that Europe needs to implement a harmonised case definition for CCHF in order to enhance notifications and to estimate the diseases burden and epidemiological trends in various areas and countries [2]. The survey revealed that all responding countries used the generic case definition of VHFs to identify and notify CCHF cases. However, this survey has some limitations since not all responding countries clearly specified the source and reference of the generic or specific case definitions.

Networking and training are key factors in ensuring a rapid and effective response to CCHF. The survey revealed that the majority of countries belong to at least one network apart from ENIVD that could assure support, management, training in the diagnosis of CCHF cases, expert consultation, exchange of experiences and protocols, and scientific support if needed. Considering that some respondents did not have procedures in place for specimen collection, processing or 


\begin{tabular}{|l|c|c|}
\hline $\begin{array}{l}\text { Serological diagnostic } \\
\text { method }\end{array}$ & \multicolumn{1}{c}{ Countries } & $\begin{array}{c}\text { Proportion of countries (relative to } \\
\text { those with CCHF serological tests) }\end{array}$ \\
\hline Commercial assay & Bulgaria, Latvia, Lithuania, the Netherlands, Portugal, Romania, Spain & $37 \%$ \\
\hline $\begin{array}{l}\text { In-house assay } \\
\begin{array}{l}\text { Commercial and in-house } \\
\text { assay }\end{array}\end{array}$ & $\begin{array}{r}\text { Grance, Serbia, Sweden, Switzerland, United Kingdom } \\
26 \%\end{array}$ \\
\hline
\end{tabular}

CCHF: Crimean-Congo haemorrhagic fever; ELISA: enzyme-linked immunosorbent assay; ENIVD: European Network for Diagnostics of 'Imported' Viral Diseases; IFA: indirect immunofluorescence assay..

transporting, the networks could also play a key role in closing this gap. The networks could also foster training via organising international workshops on CCHF diagnosis and biosafety.

Laboratory techniques are the cornerstone of CCHF diagnosis, essential for effective surveillance, management of individual patients and outbreak prevention. In 2008, the multidisciplinary consultation of CCHF experts organised by ECDC showed that according to ENIVD, 15 of 27 countries performed CCHF diagnostics [13].The current survey launched in 2012 indicated an increase to 21 of 28 countries performing CCHF diagnostics. Our results show a strong increase in the diagnostic capacity for CCHF from 2008 to the present, possibly due to the nomination of CCHF as a priority disease for the EU. However, as shown in Table 1, two WHOCC next to endemic areas (Greece and Slovenia), lost their status as reference centres for VHF. This issue has to be taken in consideration when a new reference centre in Europe will be designated in the future.

Currently, the routine laboratory diagnosis of CCHF is based mainly on the detection of the viral genome and specific IgM and IgG. Most surveyed laboratories with diagnostic capacities (21/24) followed international recommendations of combining molecular and serological methods for CCHF diagnosis $[1,28]$. This shows that most of the surveyed laboratories have essential diagnostic tools for CCHF diagnosis in place.

Molecular assays offer a rapid, sensitive and specific diagnosis of CCHF during the viraemic phase of infection up to day 16 of illness [29]. The vast majority of surveyed countries (20/21) have molecular tests available, and most of them participated in CCHF EQAs. It is highly recommended that not only endemic countries, but also neighbouring countries that lack the capacity for molecular assays try to implement them.

Of the existing molecular methods for CCHF diagnosis, the majority of respondents (18/20) used a qRT-PCR, combined or not with nested $P C R$, while the remaining two countries used a nested RT-PCR only. Moreover, in a recent molecular EQA, it is reported that nested RT-PCR performs considerably less well compared with qRT-PCRs [16]. Therefore, it is recommended that countries performing only nested RT-PCR implement capacities for a quantitative assay because qRT-PCRs offer advantages when over nested RT-PCR such as lower contamination rate, higher sensitivity and specificity, and better time-effectiveness. A factor that may limit the use of molecular diagnostic methods is the fact that sensitivity may be affected by the high diversity of CCHF genomes. For instance, it has been found that sensitivity of molecular methods was associated with the patients' country of origin [17]. A combination of commercial and in-house RT-PCR assays will probably ensure the detection of CCHFV strains despite their diversity. However, the survey reveals that 20 of 23 laboratories use in-house RT-PCR but only eight combine it with a commercial test.

Although serological methods may cover a broader spectrum of strains due to cross-reactivity, attention must be also paid to antigenic variation among CCHFV strains which may affect their sensitivity. However, combinations of ELISA and IFA, commercial or in-house, may increase the sensitivity of detection. A recent evaluation of two commercial kits (VectorBest ELISAs and Euroinmune IFA, both for IgM and IgG) revealed that efficient and well characterised serological assays and protocols are available for CCHF diagnosis [17]. Our survey reveals that all countries using the commercial ELISA also had available commercial IFAs and that half of them combined them with an in-house ELISAs that may compensate a potential lower sensitivity caused by antigenic diversity. We advise that each country assure that their methods are optimised for strains circulating in their area, or that they use an adapted method for CCHFV genotypes circulating in their country.

In addition, to assure that diagnostic methods perform with optimal accuracy, an increased effort is needed to establish EQA studies on a regular basis. In 2011, an international EQA for the molecular detection of CCHF was launched [16]. The majority of countries with areas endemic for or at risk of CCHF surveyed in our study 


\section{TABLE 3}

Laboratory preparedness and response capacities for Crimean-Congo haemorrhagic fever diagnosis in the European region, ENIVD survey, 2012 ( $\mathrm{n}=28$ countries)

\begin{tabular}{|c|c|c|c|c|c|c|c|}
\hline \multirow{3}{*}{ Countries } & \multicolumn{5}{|c|}{ Preparedness and response } & \multicolumn{2}{|c|}{ Diagnostic methods } \\
\hline & \multicolumn{2}{|c|}{ Case definition } & \multirow[b]{2}{*}{ Networks } & \multicolumn{2}{|c|}{ EQA } & \multirow[b]{2}{*}{ Diagnostic techniques } & \multirow[b]{2}{*}{ BSL } \\
\hline & $\begin{array}{c}\text { Generic } \\
\text { VHFf }\end{array}$ & $\begin{array}{l}\text { Specific } \\
\text { CCHF }\end{array}$ & & ENIVD & QUANDHIP & & \\
\hline Austria & Yes & No & ENIVD & Yes & No & PCR & $\mathrm{BSL2+}$ \\
\hline Belgium & NA & No & ENIVD & No & No & Referral & \\
\hline Bulgaria & NA & Yes $^{\mathrm{a}}$ & ENIVD, EpiSouth, CCH-FEVER & Yes & No & PCR, ELISA, IFA, VI & BSL2 \\
\hline Croatia & Yes & Yes $^{a}$ & ENIVD & No & No & PCR & $\mathrm{BSL} 3$ \\
\hline Czech Republic & NA & No & ENIVD & No & No & Referral & \\
\hline Estonia & Yes & No & ENIVD & No & No & Referral & \\
\hline $\begin{array}{l}\text { Former Yugoslav } \\
\text { Republic of } \\
\text { Macedonia }\end{array}$ & NA & Yes $^{\mathrm{b}}$ & ENIVD, EpiSouth & No & No & Referral & \\
\hline France & NA & No & ENIVD, EpiSouth, Euronet-P4 & Yes (Lyon) & No & PCR, ELISA, VI & BSL4 \\
\hline Germany & NA & Yes & ENIVD, Euronet-P4 & $\begin{array}{c}\text { Yes } \\
\text { (Hamburg) }\end{array}$ & Yes & PCR, ELISA, IFA, VI & $\mathrm{BSL} 4$ \\
\hline Greece & NA & Yes $^{c}$ & $\begin{array}{l}\text { ENIVD, EpiSouth, Arbo-Zoo-net, } \\
\text { CCH-FEVER }\end{array}$ & Yes & No & PCR, ELISA, IFA, VI & $\mathrm{BSL} 3$ \\
\hline Italy & NA & No & ENIVD, EpiSouth, Euronet-P4 & Yes & Yes & PCR, IFA, VI & BSL4 \\
\hline $\begin{array}{l}\text { Kosovo under UN } \\
\text { Security Council } \\
\text { Resolution } 1244\end{array}$ & NA & Yes & ENIVD, EpiSouth & No & No & PCR, ELISA, IFA & BSL2 \\
\hline Latvia & NA & Yes & ENIVD & Yes & No & PCR, IFA & $\mathrm{BSL} 3$ \\
\hline Lithuania & $\mathrm{NA}$ & No & ENIVD & No & No & PCR, IFA, VI & $\mathrm{BSL3}$ \\
\hline Malta & $\begin{array}{c}\text { Yes } \\
(\mathrm{ECDC})\end{array}$ & No & ENIVD, EpiSouth & No & No & Referral & \\
\hline The Netherlands & Yes & No & ENIVD & Yes & No & PCR, IFA & $\mathrm{BSL3}$ \\
\hline Norway & Yes & No & ENIVD & No & No & Referral & \\
\hline Portugal & NA & No & ENIVD & Yes & No & PCR, ELISA, IFA & $\mathrm{BSL} 3$ \\
\hline Romania & Yes & No & ENIVD, EpiSouth & Yes & No & PCR, IFA & BSL2 \\
\hline Russia & No & $\mathrm{No}^{\mathrm{d}}$ & ENIVD & Yes & No & PCR, ELISA, IFA & $\mathrm{BSL3}$ \\
\hline Serbia & Yes & Yes $^{\mathrm{a}}$ & ENIVD, EpiSouth & No & No & IFA, VI & BSL2 \\
\hline Slovakia & No & No & ENIVD & No & No & Referral & \\
\hline Slovenia & Yes & No & ENIVD, CCH-FEVER, Arbo-Zoo-Net & Yes & No & PCR, ELISA, IFA, VI & $\mathrm{BSL}_{3+}$ \\
\hline Spain & Yes & Yes $^{\mathrm{e}}$ & ENIVD, EpiSouth & Yes & No & PCR, IFA & $\mathrm{BSL3}$ \\
\hline Sweden & Yes & No & $\begin{array}{l}\text { ENIVD, CCH-FEVER, Euronet-P4, } \\
\text { Arbo-Zoo-Net }\end{array}$ & Yes & Yes & PCR, IFA, VI & $\mathrm{BSL} 4$ \\
\hline Switzerland & Yes & Yes & ENIVD & Yes & No & PCR, ELISA & BSL4 \\
\hline Turkey & NA & Yes & ENIVD, EpiSouth, CCH-FEVER & Yes & No & PCR, ELISA, IFA & $\mathrm{BSL3}$ \\
\hline United Kingdom & Yes & No & ENIVD, Euronet-P4 & $\begin{array}{c}\text { Yes (Porton } \\
\text { Down) }\end{array}$ & Yes & PCR, ELISA, IFA, VI & BSL4 \\
\hline
\end{tabular}

Arbo-Zoo-Net: Network for Capacity Building for the Control of Emerging Viral Vector Borne Zoonotic Diseases; BSL: biosafety level; CCH-FEVER: Crimean Congo Haemorrhagic Fever Network; ECDC: European Centre for Disease Prevention and Control; ELISA: enzyme-linked immunosorbent assay; ENIVD: European Network for Diagnostics of 'Imported' Viral Diseases; EpiSouth: Network for Communicable Disease Control in Southern Europe and Mediterranean Countries; Euronet-P4: European Network of Biosafety-Level-4 laboratories; EQA: external quality assessment; IFA: indirect immunofluorescence assay; NA: not available; PCR: polymerase chain reaction; QUANDHIP: Quality Assurance exercise and Networking on the Detection of Highly Infectious Pathogens project; VHF: viral haemorrhagic fever; VI: viral isolation.

a $[22,23]$.

National guides in preparation.

[24].

d Not formal case definition [25].

e [26]

EU case definition for VHF [27]. 


\section{FIGURE 3}

Biosafety levels for laboratories with Crimean-Congo haemorrhagic fever diagnostic capacities, ENIVD survey, $2012(n=24)$

A. For virus inactivation

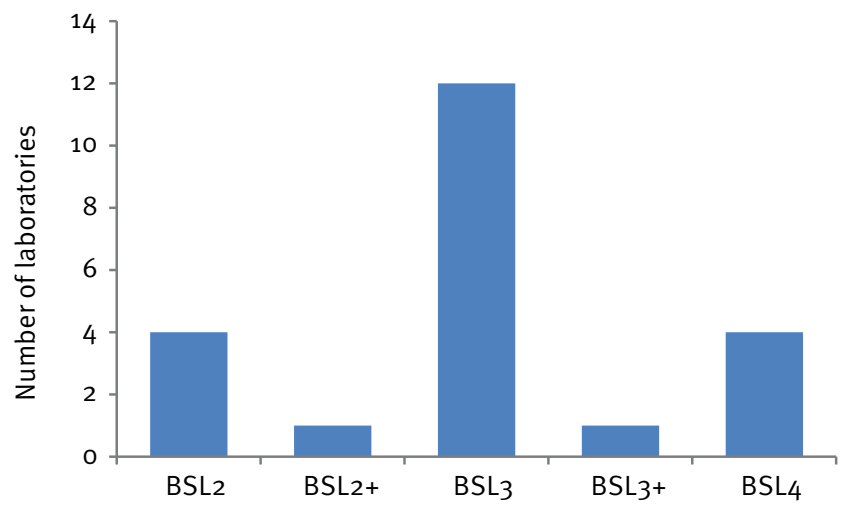

B. For virus propagation

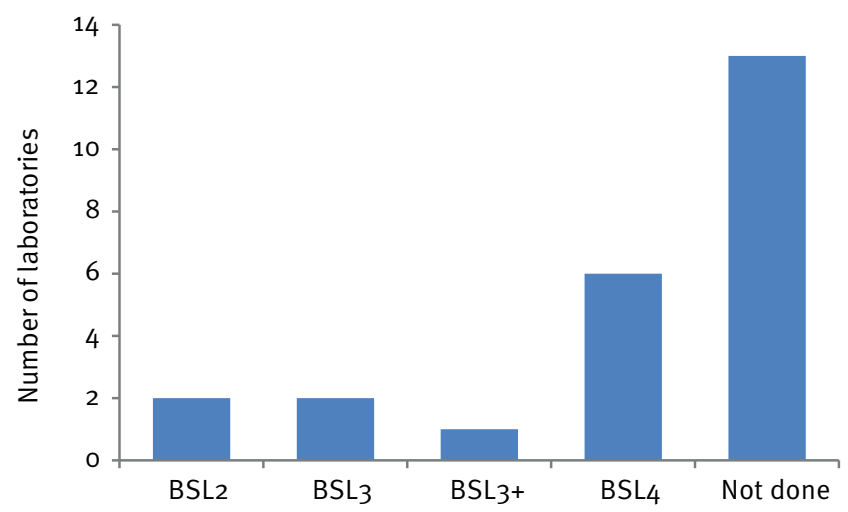

also participated in this EQA, in which 53 datasets were received from 44 laboratories worldwide, mostly European. Twenty of the datasets (38\%) met the criteria with optimal performance.

The most definite way of CCHF diagnosis is detection of viral RNA combined with detection of IgM antibodies. Virus isolation as a diagnostic tool is rarely applied because high biocontainment laboratories (BSL4) are required. None of the European $\mathrm{BSL}_{4}$ laboratories are situated in CCHF areas, and among 11 laboratories performing viral propagation, five reported that they do not work in BSL4 facilities. Three of these five laboratories were in CCHF endemic countries.

In conclusion, the main priority issues to be addresses by European health authorities are: (i) establishing rapid and reliable protocols for CCHF laboratory diagnosis together with guidelines on storage, processing and transportation of samples, (ii) nominating a Regional Reference Expert Laboratory or a WHOCC in or near the endemic areas, and (iii) a comprehensive review of the $B S L$ facilities suited to the reality in the endemic areas, their capacities and capabilities.
Acknowledgments

The authors thank to Regina Schädler for her assistance during the dissemination of the questionnaire among ENIVD members, Steen Ethelberg and Aftab Jasir for critical reading the manuscript and Silvia Herrera for her advice and support.

\section{Conflict of interest}

None declared.

Authors' contributions

MDFG, AN, AT and LF conceived and designed the study; MDFG, OD, HZ, AN and LF designed the questionnaires; LF, $M N$ and $O D$ coordinated the collection of data through the ENIVD network; MDFG, AN and LF were involved in data management and analyses; AT, HZ, OD, MN and AP contributed with data analysis; MDFG and LF drafted the manuscript; all co-authors reviewed and assisted in the editing of the final version of the manuscript.

Members of the European Network for Diagnostics of 'Imported' Viral Diseases (ENIVD)

Austria: Stephan Aberle at Medical University of Vienna, Department of Virology, Vienna. Belgium: Marjan Van Esbroeck at Institute of Tropical Medicine, Central Laboratory for Clinical Biology, Antwerpen. Bulgaria: Iva Christova at National Centre for Infectious and Parasitic Diseases, National Reference Laboratory on tick-borne diseases, Sofia. Croatia: Alemka Markotic and Ivan-Christian Kurolt at University Hospital for Infectious Diseases, Research Department Zagreb. Czech Republic: Hana Zelena at Institute of Public Health, National Reference Laboratory for Arboviruses, Ostrava. Estonia: Irina Golovljova at National Institute for Health Development (NIHD)/Health Board. France: Delphine Pannetier at Institut Pasteur, French National Reference Center for Viral Haemorrhagic Fevers, Lyon and Remi Charrel at Aix-Marseille University, Unité Emergence des Phatologies Virales, Marseille. Germany: Jonas Schmidt-Chanasit at Bernhard-Nocht Institut, Hamburg and Roman Wölfel at Institut für Mikrobiologie der Bundeswehr, München. Greece: Anna Papa at Aristotle University, Thessaloniki, National Reference Laboratory for Arboviruses. Italy: Maria Rosaria Capobianchi at National Institute for Infectious Diseases “L.Spallanzani”, Laboratory of Virology, Rome. Kosovo under UN Security Council Resolution 1244: Xhevat Jakupi at National Institute of Public Health of Kosovo, Department of Microbiology. Latvia: Jelena Storozenko at Infectology Center of Latvia, National Microbiology Reference Laboratory. Lithuania: Algirdas Griskevicius at National Public Health Surveillance Laboratory, Molecular Biology Testing Subdivision. Former Yugoslav Republic of Macedonia: Golubinka Bosevska at Institute of Health Protection of RM, Laboratory for virology and molecular diagnosis. Malta: Clive Muscat at Mater Dei Hospital, Virology Laboratory. The Netherlands: Martin Schutten at Erasmus University Hospital Rotterdam, Department of Virology. Norway: Susanne Dudman at Norwegian Institute of Public Health, Department of Virology, Oslo. Portugal: Maria Joao Alves at National Institute of Health, Centre for Vectors and Infectious Diseases Research, Águas de Moura. Romania: Cornelia Ceianu at National Institute of Public Health, National Center for Surveillance and Control of Communicable Diseases, Lab For Vector Borne Infections and Medical Entomology, Bucharest. Russia: Alexander Platonov at Central Research Institute of Epidemiology, Laboratory for zoonoses, Moscow. Serbia: Bojana Bozovic at Torlak Institute of Virology, Vaccines and Sera, National Reference Laboratory for Arboviruses. Slovakia: Boris Klempa at Institute of virology, 
Slovak Academy of Sciences, Department of Virus Ecology. Slovenia: Tatjana Avsic at University of Ljubljana, Laboratory for diagnosis of zoonoses. Spain: Antonio Tenorio at Instituto de Salud Carlos III, Laboratory of Arbovirus and Imported Viral Diseases, Majadahonda, Madrid. Sweden: Ake Lundkvist at Swedish Institute for Infectious Disease Control, Karolinska Institute Stockholm, Solna. Switzerland: Pascal Cherpillod at University Hospitals of Geneva, Laboratory of Virology. Turkey: Gulay Korukluoglu at Refik Saydam Hygiene Institute, Department of Virology, Ankara. United Kingdom: David Brown at Virus reference department, Public Health England, Colindale and Tim Brooks at Special Pathogens Reference Unit. Public Health England, Porton Down.

\section{References}

1. Whitehouse CA. Crimean-Congo hemorrhagic fever. Antiviral Res. 2004;64(3):145-60. http://dx.doi.org/10.1016/j. antiviral.2004.08.001

2. Maltezou HC, Andonova L, Andraghetti R, Bouloy M, Ergonul 0 , Jongejan $F$, et al. Crimean-Congo hemorrhagic fever in Europe: current situation calls for preparedness. Euro Surveill. 2010;15(10): pii=19504.

3. Papa A, Dalla V, Papadimitriou E, Kartalis GN, Antoniadis A. Emergence of Crimean-Congo haemorrhagic fever in Greece. Clin Microbiol Infect. 2010;16(7):843-7. http://dx.doi. org/10.1111/j.1469-0691.2009.02996.x

4. Jaureguiberry S, Tattevin P, Tarantola A, Legay F, Tall A, Nabeth $P$, et al. Imported Crimean-Congo hemorrhagic fever. J Clin Microbiol. 2005;43(9):4905-7. http://dx.doi.org/10.1128/ JCM.43.9.4905-4907.2005

5. ProMED-mail. Crimean-Congo hemorrhagic fever, fatal Germany ex Afghanistan. Archive Number 20091109.3883. 9 Nov 2009. Available from: http://promedmail.org/direct. php?id=20091109.3883

6. Atkinson B, Latham J, Chamberlain J, Logue C, O'Donoghue L, Osborne J, et al. Sequencing and phylogenetic characterisation of a fatal Crimean - Congo haemorrhagic fever case imported into the United Kingdom, October 2012. Euro Surveill. 2012;17(48): pii=20327.

7. Filipe AR, Calisher CH, Lazuick J. Antibodies to Congo-Crimean hemorrhagic-fever, Dhori, Thogoto and Bhanja viruses in southern Portugal. Acta Virol. 1985;29(4):324-8.

8. Németh V, Oldal M, Egyed L, Gyuranecz M, Erdélyi K, Kvell $\mathrm{K}$, et al. Serologic evidence of Crimean-Congo hemorrhagic fever virus infection in Hungary. Vector Borne Zoonotic Dis. 2013;13(4):270-2. http://dx.doi.org/10.1089/vbz.2012.1011

9. Jameson LJ, Morgan PJ, Medlock JM, Watola G, Vaux AG. Importation of Hyalomma marginatum, vector of CrimeanCongo haemorrhagic fever virus, into the United Kingdom by migratory birds. Ticks Tick Borne Dis. 2012;3(2):95-9. http:// dx.doi.org/10.1016/j.ttbdis.2011.12.002

10. Nijhof AM, Bodaan C, Postigo M, Nieuwenhuijs H, Opsteegh $M$, Franssen $L$, et al. Ticks and associated pathogens collected from domestic animals in the Netherlands. Vector Borne Zoonotic Dis. 2007;7(4):585-95. http://dx.doi.org/10.1089/ vbz.2007.0130

11. Kampen H, Poltz W, Hartelt K, Woelfel R, Faulde M. Detection of a questing Hyalomma marginatum marginatum adult female (Acari, Ixodidae) in southern Germany. Exp Appl Acarol. 2007;43(3):227-31. http://dx.doi.org/10.1007/ S10493-007-9113-y

12. Massad E, Coutinho FA, Burattini MN, Lopez LF. The risk of yellow fever in a dengue-infested area. Trans $\mathrm{R}$ Soc Trop Med Hyg. 2001;95(4):370-4. http://dx.doi.org/10.1016/ So035-9203(01) $90184^{-1}$

13. European Center for Disease Control and Prevention (ECDC). Consultation on Crimean-Congo haemorrhagic fever prevention and control. September 2008. Meeting report. Stockholm: ECDC; 2009 . Available from: http://ecdc.europa.eu/en/ publications/Publications/0809_MER_Crimean_Congo Haemorragic_Fever_Prevention_and_Control.pd̄f

14. Estrada-Pena A, Palomar AM, Santibanez P, Sanchez N, Habela MA, Portillo A, et al. Crimean-Congo Hemorrhagic Fever Virus in Ticks, Southwestern Europe, 2010. Emerg Infect Dis. 2012;18(1):179-80. http://dx.doi.org/10.3201/eid1801.111040

15. Ceianu CS, Panculescu-Gatej RI, Coudrier D, Bouloy M. First Serologic Evidence for the Circulation of CrimeanCongo Hemorrhagic Fever Virus in Romania. Vector Borne Zoonotic Dis. 2012;12(9):718-21. http://dx.doi.org/10.1089/ vbz.2011.0768
16. Escadafal C, Olschlaeger S, Avsic-Zupanc T, Papa A, Vanhomwegen J, Woelfel R, et al. First International External Quality Assessment of Molecular Detection of Crimean-Congo Hemorrhagic Fever Virus. PLoS Negl Trop Dis. 2012;6(6):e1706.

17. Vanhomwegen J1, Alves MJ, Zupanc TA, Bino S, Chinikar $\mathrm{S}$, Karlberg $\mathrm{H}$,, et al. Diagnostic assays for Crimean-Congo hemorrhagic fever. Emerg Infect Dis. 2012;18(12):1958-65. http://dx.doi.org/10.3201/eid1812.120710

18. Schwarz TF, Nsanze H, Longson M, Nitschko H, Gilch S, Shurie $\mathrm{H}$, et al. Polymerase chain reaction for diagnosis and identification of distinct variants of Crimean-Congo hemorrhagic fever virus in the United Arab Emirates. Am J Trop Med Hyg. 1996;55(2):190-6.

19. Duh D, Saksida A, Petrovec M, Dedushaj I, Avsic-Zupanc T. Novel one-step real-time RT-PCR assay for rapid and specific diagnosis of Crimean-Congo hemorrhagic fever encountered in the Balkans. J Virol Methods. 2006;133(2):175-9. http://dx.doi. org/10.1016/j.jviromet.2005.11.006

20. Papa A, Drosten C, Bino S, Papadimitriou E, Panning M, Velo $E$, et al. Viral load and Crimean-Congo hemorrhagic fever. Emerg Infect Dis. 2007;13(5):805-6. http://dx.doi.org/10.3201/ eid1305.061588

21. Wölfel R, Paweska JT, Petersen N, Grobbelaar AA, Leman PA, Hewson R, et al. Virus detection and monitoring of viral load in Crimean-Congo hemorrhagic fever virus patients. Emerg Infect Dis. 2007;13(7):1097-100. http://dx.doi.org/10.3201/ eid1307.070068

22. Bossi P, Tegnell A, Baka A, Van Loock F, Hendriks J, Werner $A$, et al. Bichat guidelines for the clinical management of haemorrhagic fever viruses and bioterrorism-related haemorrhagic fever viruses. Euro Surveill. 2004;9(12):pii=504.

23. European Commission. Decision No 2119/98/EC of the European Parliament and of the Council of 24 September 1998 setting up a network for the epidemiological surveillance and control of communicable diseases in the Community. Official Journal of the European Union. OJ L 268/1; 3 Oct 1998. Available from: http://eur-lex.europa.eu/legal-content/EN/TXT/ HTML/? uri=CELEX:31998D2119\&from=EN

24. Maltezou HC, Papa A, Tsiodras S, Dalla V, Maltezos E, Antoniadis A. Crimean-Congo hemorrhagic fever in Greece: a public health perspective. Int J Infect Dis. 2009;13(6):713-6. http://dx.doi.org/10.1016/j.ijid.2008.11.011

25. Organizatsiia i provedenie profilakticheskikh i protivoepidemicheskikh meropriiatii protiv Krymskoi gemorragicheskoi likhoradki. Metod. ukazaniia MU 3.1.1.248809 [Organization and implementation of prophylactic and antiepidemic measures against Crimean hemorrhagic fever. Methodological guideline 3.1.1.2488-09]. Moscow: Rospotrebnadzor Publ.; 2009. Russian.

26. Informe de situación y evaluación del riesgo de transmision de fiebre hemorrágica de Crimea-Congo (FHCC) en Espa-a. [Situation and risk assessment of transmission of CrimeanCongo haemorrhagic fever (CCHF) in Spain]. Madrid: Ministry of Health; 2011. Available from: http://www.msssi.gob.es/ profesionales/saludPublica/ccayes/analisisituacion/doc/ crimeaCongo.pdf

27. European Commission. Commission Decision of 28 April 2008 amending Decision 2002/253/EC laying down case definitions for reporting communicable diseases to the Community network under Decision No 2119/98/EC of the European Parliament and of the Council. Official Journal of the European Union. OJ L 159/46; 18 Jun 2008. Available from: http://eur-lex. europa.eu/LexUriServ/LexUriServ.do?uri=0J:L:2008:159:0046 :0090:EN:PDF

28. Drosten C, Kummerer BM, Schmitz H, Gunther S. Molecular diagnostics of viral hemorrhagic fevers. Antiviral Res. 2003;57(1-2):61-87. http://dx.doi.org/10.1016/ S0166-3542(02)00201-2

29. Burt FJ, Leman PA, Smith JF, Swanepoel R. The use of a reverse transcription-polymerase chain reaction for the detection of viral nucleic acid in the diagnosis of Crimean-Congo haemorrhagic fever. J Virol Methods. 1998;70(2):129-37. http:// dx.doi.org/10.1016/S0166-0934(97)00182-1 